\title{
Research on the Present Situation of Physical Education Teaching in Middle School under the Background of National Fitness
}

\author{
Zhi hong Yin ${ }^{1, *}$ \\ ${ }^{1}$ Physical Education Institute, Nanchang Institute of Technology, NanChang, Chain \\ *e-mail:964012041@qq.com
}

\begin{abstract}
With the acceleration of my country's economic and social development, the pressure of competition between work and life is increasing, and people are paying more and more attention to health issues. In order to promote the development of a higher level of national fitness and better meet the people's fitness and health needs, the implementation of the national fitness plan has greatly promoted the rapid development of my country's fitness and entertainment industry. This article adopts literature method, questionnaire survey method, interview method and mathematical statistics method, combined with the investigation and research on the status of physical education in middle schools in Lushan City, Jiangxi Province under the background of national fitness. The results show that the physical education situation of middle school students in Lushan City is not optimistic, and countermeasures to improve the status quo have been put forward.
\end{abstract}

Keywords-middle school physical education, national fitness, investigation

\section{INTRODUCTION}

Having a healthy body is an important factor for us to succeed, and it is also a necessary condition for us to have a happy life. my country's implementation of the "Outline of the National Fitness Program" has put forward new goals and requirements for school sports at all levels. School physical education must adapt to the requirements of the national fitness program, adapt to the development of the national economy and society, with the goal of improving students' athletic ability, health, physical fitness, and developing good exercise habits. The upsurge of participating in sports has gradually formed in schools at all levels, laying a good foundation for the establishment of a national fitness education that integrates schools, society, and families. Fitness for all is a process in which all people participate and link sports activities. In order to promote the development of physical education for middle school students under the background of national fitness, this article investigates and analyzes the status quo of physical education in middle schools in Lushan City, and finds out various problems in physical education in Lushan City. Proposed solutions and programs to promote the reform and development of physical education in some middle schools in this city. ${ }^{[1]}$

\section{RESEARCH OBJECTS AND METHODS}

\subsection{Research objects}

Lushan No.1Middle School, Liaonan Middle School, No.2Middle School, Xingzi Middle School, Huaqiao Middle School, Jiaotang Middle School and Aikou Middle School seven middle school physical education teaching as the research object.

\subsection{Research methods}

\subsubsection{Documentation}

Key words such as physical education teaching and physical education in middle schools are searched through the Internet, and relevant articles are downloaded through CNKI, sorted out, analyzed and studied in detail. At the same time, books are consulted in the library, and text materials are collected to provide theoretical support for the study of the current situation 
of physical education teaching in middle schools in Lushan City.

\subsubsection{Interview}

Using interview method, on-the-spot investigation of several schools, and the school leaders were discussed, and record the interview content, the school physical education teaching related problems were detailed, rational logic analysis.

\subsubsection{Questionnaire survey method}

90 questionnaires were distributed to seven middle school sports teachers in Lushan City, 85 questionnaires were recovered, the recovery rate was $94.4 \%$, the questionnaires were effective, the effective rate was 100 $\%$; a total of 400 questionnaires were distributed to students from seven middle schools, and 390 valid questionnaires were recovered. The recovery rate was $97.5 \%$, of which 390 were valid and the effective rate was $100 \%$.

\subsubsection{Research process and analysis}

\subsection{Survey and evaluation of the basic situation of physical education teachers in Lushan middle school}

\subsubsection{Middle school physical education teachers 'gender ratio survey}

Through a survey of physical education teachers in secondary schools, 68 of the 85 respondents were male, accounting for as high as 80 per cent. The proportion of female physical education teachers was only 20 per cent. Male teachers were four times more than female teachers. According to the requirements of physical education teachers, the general ratio of male to female is 3: 1 , which is reasonable. According to the survey, the ratio of male to female of physical education teachers in Lushan City is 4: 1, which is far beyond. The reasons are various. First, most schools pay more attention to the teaching of cultural courses, and physical education is reduced to marginal courses, which has not attracted enough attention from schools. As a result, physical education teachers are relatively weak, and the number of people who are more willing to engage in physical education teaching is reduced, resulting in gender imbalance of physical education teachers. Second, due to the influence of China ' $s$ traditional culture, the male teachers ' physical education teaching, there is a certain bias on female physical education teachers, resulting in many female physical education teachers reduce. ${ }^{[2]}$

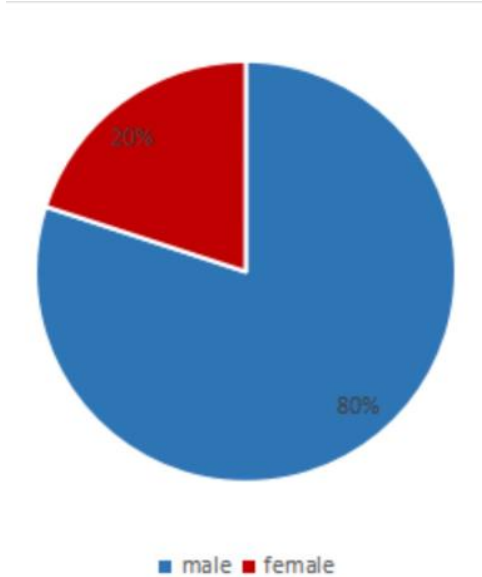

Fig. 1 Male to female ratio of middle school physical education teachers

\subsubsection{Middle school physical education teachers' age survey}

Figure2shows that: 20-29years old teachers for 23 people, the proportion of $27 \%, 30-39$ years old teachers for 28 people, the proportion of $32.9 \%$, 40-49 years old teachers for 25 peoples, the proportion of $29.4 \%$, the remaining 50-59 years old sports teachers accounted for about $10.7 \%$. The whole age composition basically presents' normal distribution', the middle school sports teacher under 40 years old is as high as $59.9 \%$, the age structure is still very reasonable in general. This shows that Lushan City in recent years increased the introduction of young physical education teachers. Figure 2 shows that sports teachers aged 20-29 accounted for $23 \%$, and the number of PE teachers aged $40-49$ accounted for $25 \%$. It can be seen that middleaged teachers exceeded the number of young teachers, and the number of PE teachers aged 50-59 was as high as $10.7 \%$. Compared with the unreasonable phenomenon of older age, the number of young teachers was still insufficient. Therefore, the government and education departments should strengthen the training and introduction of young physical education teachers. ${ }^{[3]}$

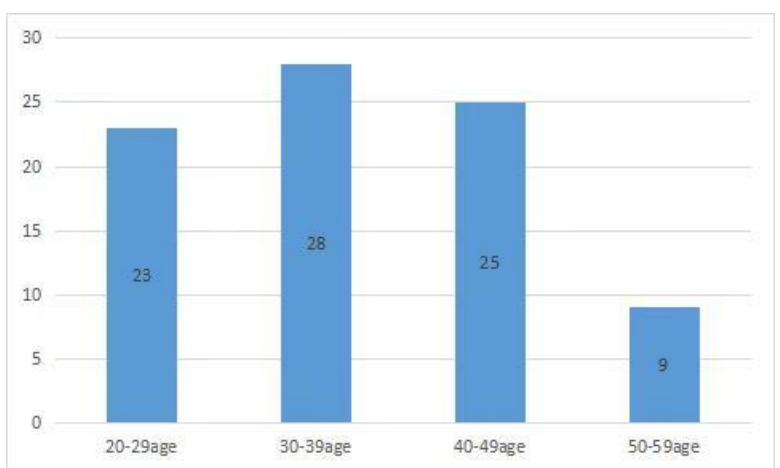

Fig. 2 Age composition of middle school physical education teachers 


\subsubsection{Education survey of physical education teachers}

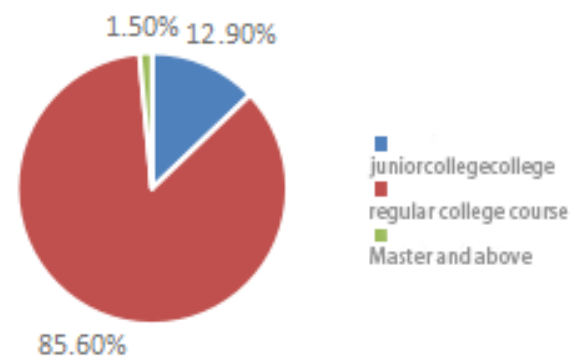

Fig. 3 Educational background of middle school sports teachers

According to the survey, $85.6 \%$ of middle school physical education teachers in Lushan have bachelor' $\mathrm{s}$ degree, $12.9 \%$ have college degree, and only $1.5 \%$ have master' s degree or above. Therefore, Lushan City middle school physical education teachers to undergraduate education, the situation tends to be normal. However, the number of highly educated (master's degree and above) sports teachers is seriously insufficient. Schools should pay attention to the introduction of more highly educated high-quality talents, improve the level of physical education teaching and scientific research in schools, and enrich and diversify the teaching content.

\subsection{Lushan City Middle School Physical Education Present Situation Investigation and Analysis}

\subsubsection{Students' satisfaction with physical education}

Due to the fierce competition in examinations for middle school students, they rarely do physical exercises in their spare time, which leads to a decline in their physical fitness and seriously affects their physical health. Among the 390 students surveyed, 110 were satisfied with normal physical education, accounting for $28.2 \%$ of the total; 160 students thought that physical education was average and physical activities were too few, accounting for $41 \%$; the remaining 120 students were satisfied with physical education. Dissatisfied, accounting for $30.8 \%$, see Table 1 below. ${ }^{[4]}$

Table 1 Student satisfaction with physical education $\mathrm{N}=$ 390

\begin{tabular}{c|c|c|c}
\hline Findings & satisfactory & general & unsatisfactory \\
\hline Number & 110 & 160 & 120 \\
\hline percentage & $28.2 \%$ & $41 \%$ & $30.8 \%$ \\
\hline
\end{tabular}

The survey results in Table 1 show that $70 \%$ of students are generally and dissatisfied with current physical education teaching. The main reasons are as follows: First, the physical education teaching items in middle schools are relatively single. In order to cope with physical examinations, many schools only do training and examination items for a long time, and do not consider students' interest and hobbies in sports activities, causing students to lose interest in physical education; second, some school sports The facilities and equipment are not perfect, the physical education teachers are insufficient, and there are even nonprofessional physical education teachers serving as physical education teachers. In addition, the number of students in physical education classes is large, and the opportunities for students to participate in sports are also reduced. Third, there are big differences in students' learning sports skills. When learning the same action, the ability to accept, the energy and time of learning are also different, and it is not possible to teach students in accordance with their aptitude.

\subsubsection{Survey of students 'initiative to participate in sports activities}

School sports teaching activities should be more diversified, stimulate students' interest, make students more active participation in physical exercise. According to the survey, $88 \%$ of the students rarely participate in extracurricular physical exercise, $92.5 \%$ of the students do not participate in morning exercises, and only about $10 \%$ of the students participate in extracurricular in extra-curricular sports activities and morning exercises. It can be seen that most students are unwilling to actively participate in sports, and this situation will become more serious. By changing the teaching methods of physical education, improving the efficiency of physical education, enriching the classroom content, students are interested in physical exercise.

Table 2 Students' participation in physical exercise questionnaire $\mathrm{N}=390$

\begin{tabular}{c|c|c|c|c}
\hline Options & never & rarely & less & often \\
\hline $\begin{array}{c}\text { extracurricular } \\
\text { practice }\end{array}$ & $39.2 \%$ & $28.8 \%$ & $19.9 \%$ & $12.5 \%$ \\
\hline $\begin{array}{c}\text { morning } \\
\text { training }\end{array}$ & $58.7 \%$ & $20.2 \%$ & $13.6 \%$ & $7.5 \%$ \\
\hline
\end{tabular}

2.4.3 Survey on the time and frequency of students ' participation in sports during class hours 
Table 3 The number of students participating in physical exercise during class hours per week $\mathrm{N}=390$

\begin{tabular}{c|c|c|c|c|c|c}
\hline Number & total number & proportion & $\begin{array}{c}\text { number } \\
\text { of boys }\end{array}$ & proportion & $\begin{array}{c}\text { number } \\
\text { of girls }\end{array}$ & proportion \\
\hline 0 & 160 & $41.2 \%$ & 52 & $13.5 \%$ & 108 & $27.7 \%$ \\
\hline 1 & 79 & $20.3 \%$ & 48 & $12.4 \%$ & 31 & $7.9 \%$ \\
\hline 2 & 54 & $13.7 \%$ & 32 & $8.1 \%$ & 22 & $5.6 \%$ \\
\hline 3 & 97 & $24.8 \%$ & 65 & $16.7 \%$ & 32 & $8.1 \%$ \\
\hline
\end{tabular}

Sports need to ensure sufficient exercise time to achieve good exercise effect. At present, middle school students are under great pressure to go to school and have heavy courses. They focus on the study of cultural courses and do not have enough time to participate in sports. The survey results show that more than $40 \%$ of the students who participate in physical exercise with zero time and frequency per week, and only a small

Table 4 Students ' physical exercise time per week $N=390$ number of students can guarantee more exercise time and frequency per week. At the same time, there are differences between boys and girls in participating in sports. The number, frequency and time of boys participating in physical exercise every week are significantly more than those of girls (see Table 3 and Table 4).

\begin{tabular}{c|c|c|c|c|c|c}
\hline hour & $\begin{array}{c}\text { total } \\
\text { number }\end{array}$ & proportion & $\begin{array}{c}\text { number of } \\
\text { boys }\end{array}$ & proportion & $\begin{array}{c}\text { number of } \\
\text { girls }\end{array}$ & proportion \\
\hline 0 & 176 & $45.1 \%$ & 58 & $14.9 \%$ & 118 & $30.2 \%$ \\
\hline $0.5-1$ & 83 & $21.3 \%$ & 50 & $12.8 \%$ & 33 & $8.5 \%$ \\
\hline $1-2$ & 63 & $16.2 \%$ & 33 & $8.5 \%$ & 30 & $7.7 \%$ \\
\hline $2-3$ & 68 & $17.4 \%$ & 57 & $14.5 \%$ & 11 & $2.9 \%$ \\
\hline
\end{tabular}

Table 5 Reasons affecting middle school students to participate in physical exercise $\mathrm{N}=390$

The results show that the weekly exercise frequency of middle school students in Lushan City is very low. On the one hand, learning requires a lot of time and energy. On the other hand, it is mainly related to the lack of school sports venues and sports facilities. Part of the school holidays sports venues and sports equipment are not open to students, resulting in obvious lack of student sports activities.

\subsubsection{Analysis of Factors Affecting Middle School Students' Participation in Physical Exercise}

The survey results show that there are two main factors affecting students' exercise : one is that there is little time for exercise during class hours, accounting for $51.6 \%$; the other is that there is no interest in sports, accounting for $14.3 \%$, which is also a subjective and objective factor. Other reasons, school sports infrastructure is not perfect, the teaching content of sports classroom boring and so on. There are several aspects of this situation: students ' examination competition is fierce, learning pressure increases, most of the time is spent on the study of cultural courses, not enough time to participate in physical exercise. In addition, physical exercise cannot be supported by schools and parents, because sports activities need to take more time, and there will be injuries, afraid of affecting academic performance.

\begin{tabular}{c|c|c}
\hline Influencing factors & Number & proportion \\
\hline $\begin{array}{c}\text { Heavy learning tasks and } \\
\text { lack of time }\end{array}$ & 201 & $51.6 \%$ \\
\hline Not interested in sports & 56 & $14.3 \%$ \\
\hline $\begin{array}{c}\text { Lack of sports venues } \\
\text { and equipment }\end{array}$ & 49 & $12.5 \%$ \\
\hline Television, online games & 34 & $8.7 \%$ \\
\hline dull classroom teaching & 24 & $6.2 \%$ \\
\hline $\begin{array}{c}\text { Parents do not support } \\
\text { enough }\end{array}$ & 19 & $4.8 \%$ \\
\hline Sports costs too high & 7 & $1.9 \%$ \\
\hline
\end{tabular}

\subsection{Lushan City middle school sports venues, equipment and facilities present situation investigation}

\subsubsection{Equipped sports infrastructure of middle schools in Lushan City}

Through the field survey of 30 middle schools in Lushan City, the survey results are shown, mainly on sports venues and sports equipment. The results show that the sports facilities and sports equipment of middle schools in Lushan City are not very perfect. Only $29 \%$ of the schools meet the basic requirements of the state, more than $70 \%$ of the schools do not meet the requirements, and even some schools have serious shortage of sports facilities. 


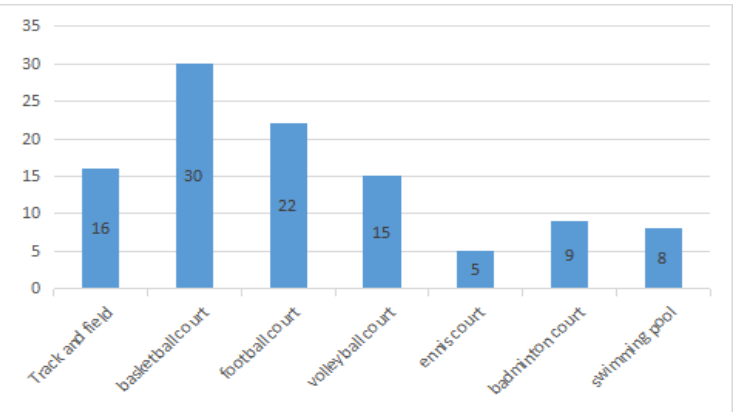

Fig. 4 Number of schools with various sports venues

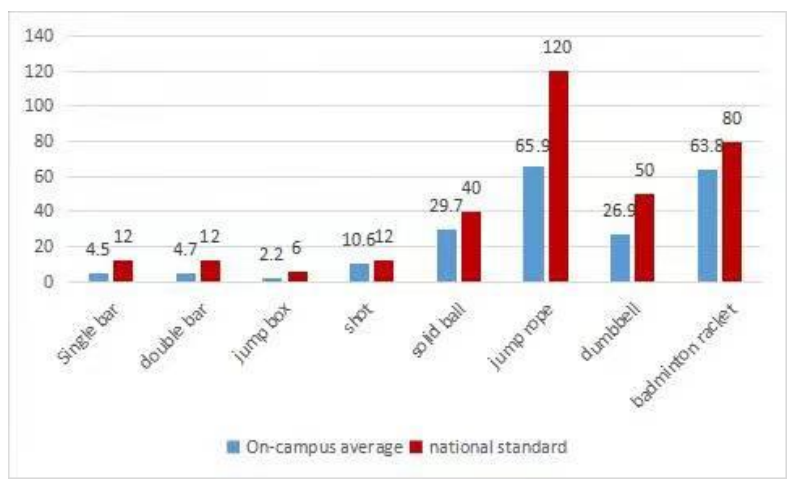

Fig. 5 The equipment of sports equipment

Figure 4 shows that all schools are only equipped with basketball courts, and other sports venues are not fully equipped. Gymnastics equipment is even scarce. Most schools do not have gymnastic equipment such as horizontal bars, parallel bars, and jumping boxes, which are far below national standards. The reason is that school leaders do not pay enough attention to physical education, insufficient government financial support, and insufficient school sports funds. ${ }^{[5]}$

\subsubsection{Lushan City Middle School Sports Facilities Opening Situation}

Physical exercise has become an important part of national fitness activities. At present, Lushan City has 289 sports venues, most of which belong to schools, accounting for $77 \%$. The survey found that $50 \%$ of middle school basketball courts and football courts are open to the public for free, and the outdoor facilities are mainly open. The reasons are as follows: First, opening up sports facilities and increasing the frequency of use will accelerate the damage and aging of facilities and equipment, increase sports investment, and burden the government's finances. The second is to open up school sports facilities, and some idle people from the society enter the campus, which disrupts normal teaching order and brings unsafe factors to students.

\section{Conclusions}

In the context of the implementation of the National Fitness Program, the investigation and analysis of the current situation of physical education in Lushan Middle School show that the students' class situation is not optimistic, which leads to the decline of students' physical fitness and difficulty in improving their sports level. The proportion of obesity and poor eyesight among middle school students is on the rise. To change the status quo of physical education in middle schools, the following points should be achieved: (1) Lushan City Education Department revises physical education content and changes teaching methods. (2) Pay attention to cultivating students' concept of lifelong exercise. (3) Physical education teachers play a leading role in the teaching activity system to ensure the quality of teaching. (4) Sports activities with students as the main body, fully consider students' feelings. Thus forming a virtuous circle will promote the reform of middle school physical education to a new level.

\section{ACKNOWLEDGMENT}

Humanities and Social Sciences Project of Nanchang Institute of Technology Project No. NLSK-21-18.

\section{REFERENCES}

[1] Lin Bijuan. Junior high school entrance examination in sports. Interest Game Analysis [ D ]. Fujian Normal University 2014

[2] Zhu Liyu. New China in different periods of primary and secondary school physical education syllabus comparative study [D] .Suzhou University 2014

[3] The basic characteristics of physical education in primary and secondary schools in the United States. 'Journal of Nanjing Institute of Physical Education (Social Science Edition)'. Issue 3 of PKU. 2013 included by Beijing University' s Chinese Core Journal List. Yang Qingqiong. Bull run. Li Danyang.

[4] Research on the current situation and countermeasures of physical education in primary and secondary schools in poor counties of Hubei Province. PKU included by Beijing University ' s Chinese Core Journal List. CSSCI included by Nanjing University 's Core Journal List. Liu Gang. Wang Zhe. Liu Anqing.

[5] The American primary and secondary school physical education curriculum standard to our country enlightenment. ' Teaching and management (middle school edition). ' Issue 2, 2015, included by Peking University ' s ' Chinese Core Journal List '. Chen Ronghao. Chen Qingguo. 